\title{
Autonomia da música e o papel do compositor na vanguarda pós-19501
}

\author{
ÍSIS BIAZIOLI DE OLIVEIRA 2 \\ ECA/USP (isis.biazioli@gmail.com) \\ MÁRIO VIDEIRA \\ ECA/USP (mario.videira@usp.br)
}

\section{I.}

omo bem notou o musicólogo alemão Carl Dahlhaus, o conceito de "obra musical" aparece relativamente tarde na história da música, e sua consolidação esteve intimamente ligada à instituição burguesa dos concertos públicos e ao processo de autonomização da música. Com efeito, "a ideia de que a música, mesmo a música desprovida de texto, pode ser ouvida por si mesma, sem estar ligada ao acompanhamento de uma ação ou cerimônia, não é autoevidente" (DAHLHAUS, 1990, p. 221). Ainda segundo Dahlhaus (1990), para que a música possa se apresentar como "obra", é necessário que já esteja consolidado o que se convencionou chamar de "escuta formal" e que o ouvinte seja capaz de apreender a forma em seus aspectos lógicos e arquitetônicos.

Um dos principais defensores da autonomia estética da música foi o crítico Eduard Hanslick (1825-1904). No ensaio Do Belo Musical, publicado pela primeira vez em 1854, o autor

\footnotetext{
${ }^{1}$ Este artigo é a revisão de trabalho apresentado nas VI Jornadas de Investigación de la Facultad de Humanidades y Ciencias de la Educación, encontro realizado na Universidad de la República, em Montevidéu, entre os dias 7 e 9 de outubro de 2015.

${ }^{2}$ A autora recebe bolsa de doutorado (processo $n^{\circ} 2015 / 04762-8$ ) da Fundação de Amparo à Pesquisa do Estado de São Paulo (FAPESP). As opiniões, hipóteses e conclusões ou recomendações expressas nesse material são de responsabilidade dos autores e não necessariamente refletem a visão da FAPESP.
} 
procura fundamentar uma autonomia da obra musical baseada no próprio objeto artístico, e não em seu efeito sobre o sujeito. Questionando sobre a natureza do belo em música, Hanslick propõe:

É um belo especificamente musical. Com isso, entendemos um belo que, sem depender e sem necessitar de um conteúdo exterior, consiste unicamente nos sons e em sua ligação artística. [...] Se me perguntarem, então, o que deve ser exprimido com esse material sonoro [conjunto de notas que podem formar melodias, harmonias e ritmos diversos] respondemos: ideias musicais. Mas uma ideia musical perfeitamente expressa já é um belo independente, é uma finalidade em si mesma, e não só um meio para a representação de sentimentos e ideias. (HANSLICK, 1992, p. 61-62)

0 argumento de Hanslick valoriza o interesse pelo material musical em si e pela técnica composicional. Por defender a ideia de que a música deve ser apreciada por ela mesma, como discurso autônomo e portador de senso e lógica estritamente musicais (HANSLICK, 1992, p. 66), considera-se que o autor inaugura também a corrente formalista no âmbito da arte dos sons. No entender de Hanslick, a fruição estética de uma obra de arte corresponderia "ao ato do ouvir atento, na consideração sucessiva das formas sonoras" (VIDEIRA, 2006, p. 110 - grifo nosso).

Muitos dos critérios estabelecidos por Hanslick serão retomados no início do século $\mathrm{XX}$, pelo compositor vienense Arnold Schoenberg (1874-1951). No célebre ensaio "Brahms, o progressista", apresentado originalmente como uma conferência em 1933, Schoenberg defende a possibilidade de se escrever música com um sentido de lógica e economia, apresentando ao ouvinte ideias musicais. Esse ideal de uma lógica implacável, capaz de desenvolver uma ideia musical até suas últimas consequências, pressupunha uma organização formal capaz de tornar inteligível ao ouvinte a apresentação dessas ideias musicais. Em diversos textos, Schoenberg afirma que "a forma nas artes, e especialmente na música, tem como principal objetivo a compreensibilidade" (SCHOENBERG, 2010, 
p. 215), ou seja, o ouvinte deve ser capaz de seguir uma ideia, seu desenvolvimento e as razões para esse desenvolvimento.

Quando Schoenberg e seus discípulos propuseram-se abandonar o sistema harmônico tonal estabelecido desde o Barroco, perceberam a dificuldade de manter um discurso compreensível que se estendesse no tempo sem o auxílio de um sistema que norteasse a organização harmônica da música. As primeiras obras atonais de Schoenberg e seus discípulos destacavam-se por sua extrema expressividade e por sua extraordinária brevidade, colocando um problema para seus criadores: parecia impossível compor peças de organização complicada ou de grande duração (SCHOENBERG, 2010, p. 217). Um pouco mais tarde, Schoenberg começaria a compor obras mais extensas recorrendo ao apoio de textos ou poemas. No entanto, "o desejo por um controle consciente dos novos meios e formas [exclusivamente musicais] irá surgir na mente de todo artista, e ele desejará conhecer conscientemente as leis e regras que governam as formas que ele concebeu" (SCHOENBERG, 2010, p. 218). Como conseguir ordem, lógica, forma e compreensibilidade num campo sonoro ainda novo para todos: compositores e ouvintes?

Com o foco da reflexão no material musical, Schoenberg elabora um método composicional que, pela primeira vez, não era o resultado de uma prática consolidada com o tempo. Tratava-se de uma proposta, inicialmente abstrata, que permitia escrever uma música em que as doze alturas do total cromático não estivessem hierarquizadas a princípio, como no sistema tonal: esse método ficou conhecido como dodecafonismo. A organização das alturas (série) passou a ser, então, escolhida antes do início de cada composição. É como se o compositor tivesse que criar para cada obra um novo sistema de prioridades e de potencialidades intervalares que seriam exploradas ou refutadas durante a escrita musical em si. Não existiriam, para essa música, paradigmas sonoros (acordes, polaridades de tensão-relaxamento, nem um contexto que garantiria a priori o que seria dissonância ou consonância) que se aplicassem a uma vasta gama de obras musicais, como era o caso da tonalidade. A cada nova criação, compositor e ouvinte estavam entregues a um mundo totalmente singular. A 
elaboração do que Schoenberg chamou de método, o dodecafonismo, propiciaria, então, um grau extremo de lógica e coerência musicais fundadas na pré-organização das alturas.

\section{II.}

Após o fim da II Guerra Mundial, empreendeu-se um enorme esforço para a reconstrução da Europa devastada. Por um lado, o Plano Marshall prometia recuperar a situação econômica e de infra-estrutura da Europa. Por outro, iniciativas para uma reconstrução moral que marcassem o fim dos ideais nazistas geraram inúmeros incentivos a tudo aquilo que o regime derrotado repudiava. $\mathrm{Na}$ música, isso significou a valorização da música experimental. Teatros, casas de ópera, rádios, salas de concertos, todos estavam atentos à música de vanguarda. Foi nesse período, ainda no final da década de 1940, que foram criadas, em uma pequena cidade da Alemanha Ocidental, Darmstadt, os Cursos Internacionais de Férias para a Música Nova (Internationalen Ferienkurse für Neue Musik). Nos cursos de Darmstadt, como ficaram conhecidos, compositores do mundo inteiro se encontravam no verão para discutir, ter aulas, tocar e ouvir experiências musicais contemporâneas. A recuperação da escuta e prática da música dodecafônica e das propostas de Schoenberg e seus alunos, na Europa, esteve intimamente ligada a esses $\operatorname{cursos}^{3}$ (STEWART, 1991, p. 265267).

Durante a vigésima edição dos cursos de Darmstadt, no ano de 1965, realizou-se um congresso intitulado "Forma na Nova Música". As conferências proferidas por compositores como György Ligeti, Earle Brown e Maurício Kagel, bem como teóricos da envergadura de Theodor W. Adorno e Carl

\footnotetext{
3 No período da II Guerra, o dodecafonismo tinha sido considerado por Hitler como prática artística degenerada e seu cultivo ficou praticamente isolado no território estado-unidense. Se não fossem os cursos de Darmstadt, nem mesmo Pierre Boulez teria informações sobre o dodecafonismo, e essa prática estaria restrita à América do Norte. (STEWART, 1991, p. 265).
} 
Dahlhaus, foram publicadas em 1966, no décimo volume dos Darmstädter Beiträge zur Neuen Musik (PALAND, 2007, p. 87) ${ }^{4}$. Em seu artigo sobre a correspondência entre Ligeti e Adorno, o musicólogo Peter Edwards informa:

Ligeti relata ter assistido a conferência de abertura realizada no dia 20 de julho por Adorno, e dedicada a Pierre Boulez. Adorno, contudo, desconhecia o conteúdo da conferência de Ligeti, proferida em duas partes nos dias 24 e 30 de julho de 1965, e escrita com a assistência de Carl Dahlhaus. Ligeti recorda: 'Então ele [Adorno] me escreveu uma carta incrivelmente entusiástica, dizendo que havíamos tido os mesmos pensamentos independentemente um do outro' (EDWARDS, 2010, p. 252).

É justamente a partir das colocações de György Ligeti, Pierre Boulez, Theodor Adorno e Carl Dahlhaus, apresentadas nesse curso de 1965, que guiaremos nossa discussão sobre o que cada um desses pensadores acreditava serem os problemas

158 e os caminhos para a Nova Forma Musical, bem como os possíveis pontos de convergência e divergência entre eles. Nossa investigação é complementada, ainda, por outros textos desses autores sobre a questão da forma a partir da década de 1950.

\section{III.}

Como se sabe, apesar de Schoenberg ter proposto uma nova linguagem melódico-harmônica, tanto ele quanto seus alunos, Berg e Webern, reafirmaram sempre o retorno a formas antigas (suíte, variações, forma sonata). No caso de Schoenberg e Berg, mais do que o retorno às formas antigas, mantinham-se também as já tradicionais categorias da música romântica (a construção fraseológica, a contraposição entre melodia e acompanhamento, etc.).

\footnotetext{
${ }^{4}$ A conferência de Pierre Boulez, intitulada "Périforme" não foi incluída nesse volume, tendo sido publicada em Les Lettres Françaises (16 de junho de 1966), sem referência ao seu contexto original (BOULEZ, 1990, p. 100).
} 
Para alguns teóricos, Webern foi mais ousado. Embora o compositor jamais tenha abandonado as formas tradicionais, o compositor teria conseguido construir um discurso que problematizava as antigas categorias e propunha novas percepções. Ele havia feito uma interpretação radical dos princípios colocados por Schoenberg, e considerava que a composição com doze sons teria atingido "em coerência um grau de perfeição jamais verificado anteriormente" (WEBERN, 1984, p. 43). A pulverização de notas espalhadas pela tessitura e isoladas por grandes momentos de silêncio em suas obras, por exemplo, permitiu, segundo Boulez (1995, p. 328), a relativização da tradicional dicotomia entre horizontal (melodia) e vertical (harmonia), e assim Webern teria criado uma nova dimensão em música: a dimensão diagonal. Igualmente, a organização simétrica das notas, e até das formas - empregadas em muitas das obras de Webern, como na Sinfonia Op. 21 - gerariam, segundo Ligeti (2007, p. 100-101), um questionamento acerca da construção temporal linear e teleológica da música clássico-romântica.

Como se pode perceber, não foi por acaso que Webern foi escolhido pelos jovens compositores da geração posterior à Segunda Guerra como ideal estético a ser seguido em música. 0 papel de destaque que as obras de Webern assumiram para esses jovens compositores representava, na visão de Boulez, o reconhecimento de que teria sido Webern quem esteve sensível ao alcance do dodecafonismo e o estendeu, da linguagem, para a arquitetura de suas obras ${ }^{5}$. A crítica ao que

5 "(...) em Webern, a evidência sonora é atingida pela geração da estrutura a partir do material. Estamos falando do fato de que a arquitetura da obra deriva diretamente da disposição da série. [...]. Enquanto Berg e Schoenberg limitam de certo modo o papel da escrita serial ao plano semântico da linguagem - a invenção de elementos que serão combinados por uma retórica não serial - em Webern, o papel dessa escrita [serial] se estende ao plano da retórica. É, portanto, com Webern que irrompem na sensibilidade adquirida os primeiros elementos de uma forma de pensamento musical irredutível aos esquemas fundamentais dos universos sonoros que o precederam" (BOULEZ, 1995, p. 24 - grifo do autor). 
Boulez considerava como propostas anacrônicas e incoerentes de Schoenberg e Berg recaem justamente na recusa que esses compositores tiveram em atender, em larga escala, a uma nova sintaxe que correspondesse às reais potencialidades do novo material escolhido. ${ }^{6}$ Tal visão valoriza a organização dos materiais musicais empregados por Webern e encontra, ali, o "belo especificamente musical" de suas obras.

Na opinião de Adorno, a escolha de Webern como modelo para as propostas poéticas das vanguardas de Darmstadt na segunda metade do século XX era uma confirmação de que a Segunda Escola de Viena havia sido compreendida a partir de um ponto de vista formalista e objetivista. Criticando a exacerbação dessa corrente formalista, para Adorno, a própria criação de um método de composição, dodecafônico, que auxiliasse o compositor diante da escrita com os doze sons cromáticos era o primeiro passo para o que ele, mais tarde, percebeu como o problema das composições da década de 1950: a gradual perda da liberdade durante o ato de composição. 0 segundo passo teria sido eleger o mais hermético entre os três compositores da Segunda Escola de

\footnotetext{
6 "Berg e Schoenberg, em compensação, a partir do momento em que se estabeleceram os princípios seriais, passaram imediatamente a edificar obras musicais de complexidade pelo menos iguais às obras precedentes. Esse fato levou-os, naturalmente, a se apoiarem em princípios de composição anteriores aos da técnica serial (forma sonata, rondó, ou formas pré-clássicas: giga, passacaglia, coral etc.). A escrita serial passa a ser considerada como consolidação e codificação do cromatismo, e como meio passível de unir as diferentes partes do discurso musical por uma espécie de mínimo denominador comum. De certo modo, o princípio da escrita serial está a serviço de um pensamento musical que não rejeita a mentalidade anterior, da qual nasceu. ( 0 caso limite é, evidentemente, a linguagem tonal reconstituída no interior da série). Aí existe uma ardilosa imbricação de presunção e timidez. Presunção, é claro, pelo desembaraço com que, utilizando uma linguagem cujos meios de articulação ainda estavam mal definidos, tentava-se a grande forma com toda a sua complexidade. E não menor timidez, pela falta de confiança nas propriedades específicas dessa linguagem, à qual se dava um suporte preestabelecido e que era extrínseco a elas" (BOULEZ, 1995, p. 26)
} 
Viena - Anton Webern - como o símbolo da nova música. Isso porque, para o filósofo, o formalismo weberniano colocava em evidência demasiada as necessidades do material na escrita composicional, em detrimento da expressividade.

Mesmo no primeiro dos formalistas musicais, o papel do sujeito na composição musical esteve sempre pressuposto. Hanslick, afirmava explicitamente não reconhecer nenhuma beleza sem uma participação do espírito: "ao insistirmos na beleza musical, não excluímos o conteúdo espiritual, mas o postulamos como exigência" (HANSLICK, 1992, p. 65). Além disso, as coligações de notas "em cujas relações repousa o belo musical, são obtidas não por alinhamento mecânico, mas pela livre criação da fantasia. A força espiritual e a particularidade dessa determinada fantasia imprimem sua marca característica ao produto" (HANSLICK, 1992, p. 67-68, grifos nossos) ${ }^{7}$.

Sem negar que os "avanços no controle sobre o material da música" (ADORNO, 1998, p. 276), desde o dodecafonismo, não podiam mais ser revertidos, Adorno reclama pelo resgate da "força espiritual" e da "livre criação da fantasia", como ponderara Hanslick ainda no século XIX, para reverter a exclusão da liberdade compositiva do sujeito em relação nas obras da segunda metade do século XX. Liberdade compositiva que, segundo ele, vinha sendo gradativamente solapada desde o início daquele século. Na década de 1950, isso aparecia claramente em dois movimentos opostos da música de vanguarda: de um lado, na mecanização de procedimentos do serialismo integral (super-determinação a partir de inúmeros materiais pré-composicionais) e, por outro, na arbitrariedade da música indeterminada (inclusão do acaso na música).

\footnotetext{
7 Cabe ressaltar que nas composições da Segunda Escola de Viena, mesmo as de Webern, nunca a expressividade foi ignorada. Contudo, é relevante perceber que, dentre tantos aspectos poéticos de suas obras, Boulez e seus contemporâneos elegeram construir seus discursos e escala de valores levando em conta, principalmente, aspectos formalistas e objetivos, como bem percebe Adorno.
} 
Partilhando da mesma crítica a alguns exemplos da música de 1950, Ligeti também observa a similaridade entre os resultados dessas duas práticas de pressupostos tão distintos:

A indiferença de tais estruturas, resultado de manipulações com o acaso, está estritamente relacionada com a indiferença dos produtos automáticos da música serial primitiva. [...] Basicamente não existe diferença entre os resultados automáticos e os produtos do acaso: o que é totalmente determinado se iguala ao que é totalmente indeterminado. [...] Em ambas se encontra o mesmo hábito típico: pausaacontecimento-pausa-acontecimento-pausa-etc.; embora os momentos de 'acontecimento' estejam estruturados de maneira diferente e as pausas tenham diferentes durações, o resultado é tanto mais nivelado quanto mais diferenciados forem os momentos de 'acontecimento' e pausa (LIGETI, 2007, p. 91-92).

Adorno chama a atenção para esse nivelamento 162 mencionado por Ligeti, apontando para o risco da perda de tensão nessas duas práticas musicais. Os dois termos dessa antinomia - a saber, o dilema entre o serialismo integral e a música indeterminada - comportam-se de maneira similar a esse respeito. Embora a prática da indeterminação e do serialismo integral partissem de processos composicionais opostos (o abandono da Arte ao acaso e ou sua subserviência às super-determinações das pré-estruturas), ambas as práticas pareciam chegar em um mesmo ponto de incomunicabilidade, de indiferenciação na escuta. $\mathrm{Na}$ opinião de Adorno, compositores como John Cage, por exemplo, tendiam à renúncia de qualquer tipo de controle sobre a música. 0 objetivo da escolha por essa renúncia seria, para Adorno, "transformar em força estética o que era fraqueza do eu psicológico" (ADORNO, 1998, p. 283 - grifo nosso).

Embora concordasse com o posicionamento de Adorno em relação à música indeterminada e super-determinada, Boulez distingue diferentes causas para esses dois problemas da música de seu tempo. Para o compositor francês, a renúncia do papel do compositor pela aleatoriedade descortinava uma fraqueza artística, uma fraqueza da técnica composicional: 
A forma mais elementar da transmutação do acaso estaria na adoção de uma filosofia colorida de orientalismo que encobrisse uma fraqueza fundamental na técnica de composição; seria um recurso contra a asfixia da invenção, recurso de veneno sutil que destrói qualquer embrião de artesanato; eu qualificaria esta experiência - se é que isso é experiência, o indivíduo não se sentindo responsável por sua obra, simplesmente se atirando por fraqueza inconfessada, por confusão e por alívio temporário em uma espécie de magia pueril - eu qualificaria então essa experiência de acaso por inadvertência. Em outras palavras, o acontecimento ocorre como pode, sem controle (ausência voluntária, embora não por mérito, mas por incapacidade). (BOULEZ, 1995, p. 43).

Por outro lado, o erro em se submeter cegamente a esquemas fechados seria, segundo Boulez, uma "busca desesperadamente estéril da força combinatória" e não, como os primeiros, incapacidade técnica. Receosos de contradizer o material empregado na obra por escolhas subjetivas errôneas ou anacrônicas - como teriam feito Schoenberg e Berg segundo opinião de Boulez - esse segundo grupo achava possível ter um domínio completo de todas as potencialidades do material empregado e acabavam também abandonando a composição, só que para combinações matemáticas.

Existe, no entanto, uma forma mais venenosa e mais sutil de intoxicação. [...] A composição visa alcançar a mais perfeita, a mais macia, a mais intocável objetividade. E por que meios? A esquematização, simplesmente, substitui a invenção; a imaginação - subserviente - limita-se a dar origem a um mecanismo complexo e é este que se encarrega de engendrar as estruturas microscópicas e macroscópicas até chegar ao esgotamento das combinações possíveis, o que indica a conclusão da obra. Admirável segurança e poderoso sinal de alarme! Quanto à imaginação, trata de não intervir a meiocaminho: isto poderia perturbar o caráter absoluto do processo de desenvolvimento introduzindo o erro humano no desenrolar de um conjunto também perfeitamente deduzido: fetichismo do número que conduz ao fracasso puro e simples. Mergulhamos num desenvolvimento estatístico que não tem valor maior que qualquer outro. [...] Aqui existe mais manha e a confissão espontânea de fraqueza [como no 'acaso por inadvertência'] se transforma em uma busca 
desesperadamente estéril da força combinatória, em uma recusa selvagem do arbítrio, este novo diabolus in musica. (BOULEZ, 1995, p. 44).

Além da "busca desesperada" por uma coerência absoluta e inabalável da organização do material, Ligeti entende o fetichismo do esquema como consequência do próprio pressuposto do serialismo integral: o da eliminação completa das hierarquias tradicionais em favor de inúmeros esquemas pré-composicionais que determinam e engessam a organização dos elementos musicais de uma composição.

Uma vez eliminadas as relações hierárquicas, afrouxadas as pulsações métricas simétricas, transpostos os graus de duração, de intervalos e de timbres das distribuições seriais; torna-se cada vez mais difícil controlar os contrastes; um processo de nivelamento começa a impor-se a toda forma musical. Quanto mais integral for a pré-formação das relações seriais, maior será a entropia da estrutura resultante. [...] Aqui, a montagem das séries significa que cada elemento aparece no contexto com igual frequência e igual peso. Isso leva infalivelmente ao aumento da entropia. Quanto mais densa for a rede de operações levadas a cabo como material pré-organizado, maior será o grau de nivelamento do resultado (LIGETI, 2007, p. 91-92).

Assim, Adorno, Boulez e Ligeti parecem concordar em um ponto: tanto no primeiro grupo de compositores - que apelam para o emprego inadvertido do acaso - quanto no segundo - daqueles que se escondem no abandono ao esquema fixo - esteve-se, durante a segunda metade do século $\mathrm{XX}$, fugindo do problema central da composição, ou seja, do lugar do sujeito e de suas escolhas no processo criativo. Afinal, essas escolhas demonstrariam se o seu compositor estava ou não alinhado às grandes exigências estéticas do período. Como estar alinhado às necessidades de um material essencialmente novo, sem cair em preconceitos que antes serviam bem aos materiais do passado, mas que agora não passariam de anacronismos da forma e da estrutura? Como estar apto a fazer escolhas livres, mas ainda coerentes sobre um material sem precedentes? 
IV.

Embora tanto Theodor Adorno, quanto os compositores Pierre Boulez e György Ligeti concordassem com o problema de parte das músicas do pós-1950 - ou seja, obras que são o resultado da recusa crescente do arbítrio do sujeito criativo nas determinações compositivas -, suas colocações diferem significativamente sobre quais seriam os melhores caminhos para a retomada do papel do compositor no ato da criação.

Ainda assim, todos os três parecem também concordar que desde a alteração drástica da morfologia do material musical pela proposta dodecafônica, surgira uma necessidade pungente de se pensar uma nova forma musical, uma organização dos elementos que estivesse de acordo com as características do novo material musical. Para Boulez, "é lógico que a uma morfologia nova correspondam uma sintaxe, uma retórica e uma sensibilidade novas." E criticando duramente aqueles que optaram por manter esquemas formais do passado em nome de uma "tradição", Boulez completa: "um 'classicismo dodecafônico' é, portanto, impensável e traz em si o próprio fracasso, fruto da incoerência" (BOULEZ, 1995, p. 27).

Ligeti, alguns anos mais tarde, tira o tom crítico evidente nas colocações de Boulez, e quase naturaliza a relação entre inovação da linguagem e da forma musical. Como se não pudesse existir outra proposta, diz: "a técnica e a fantasia variam em relação constante e recíproca; cada novidade artesanal fermenta toda a bagagem intelectual e cada modificação dessa bagagem impõe revisões contínuas do processo compositivo" (LIGETI, 2007, p. 85).

Adorno (1998, p. 280-281) concorda com seus colegas ao colocar que "o material sonoro disponível é diferente nas diversas épocas, e não é possível negligenciar essas diferenças ao considerar a forma concreta da obra". De acordo com Adorno, "['o material'] nada mais é que o estado das forças produtivas de uma época que é objetificado e refletido criticamente, e com o qual o compositor é necessariamente confrontado" (ADORNO, 1998, p. 281). Não se deve, portanto, pensar em restaurar categorias antigas (tais como: antecedente 
e consequente, tensão e resolução, continuação, desenvolvimento, etc). Contudo, Adorno não deixa de sublinhar que categorias musicais - mesmo que completamente transformadas e adequadas aos novos materiais - são indispensáveis para se conseguir a articulação compreensível dos materiais (ADORNO, 1998, p. 282).

Uma pista de como Adorno considera possível forjar essa nova forma aparece justamente na sua descrição sobre o processo criativo. 0 espírito criador deveria, segundo Adorno, operar, justamente "onde a obra celebra a abdicação da mente" (ADORNO, 1998, p. 270). E mais, esse espírito deveria estar liberto das exigências externas, mesmo da racionalização formalista e objetificada, para que pudesse compreender e, assim, atender às demandas do material em si: "quanto mais completamente o artista se abandonar ao seu tema, tanto melhor será a obra. Sua submissão às exigências que se lhe apresentam desde o primeiro compasso pesa infinitamente mais do que a intenção do artista" (ADORNO, 2010, p. 97). Contudo, como vimos anteriormente, esse "abandonar-se ao seu tema" não deve se deixar cair nas armadilhas das fáceis decisões que, ao repetirem o passado, tornam-se anacrônicas e reproduzem as "inconsistências da música nova"; nem devem obedecer cegamente às potencialidades do material, excluindo seu criador do processo de composição, não se pode fazer uma "música explicada mediante diagramas" (ADORNO, 1998, p. 269). Pelo contrário, a composição musical:

Seria um processo concreto de uma crescente unidade entre partes e todo, e não a sua subsunção sob um conceito abstrato supremo, junto à justaposição das partes. Mas o processo concretizador jamais pode ser garantido apenas pelo material. [...] se a substância deve se desenvolver organicamente, é necessária a intervenção do sujeito ${ }^{8}$, ou

${ }^{8}$ Adorno (1998, p. 300-301), ao comentar uma das categorias do conceito de música informal ("expressão"), ressalta o fato de que o sujeito da composição musical e o sujeito psicológico não são idênticos. Isso significa que a expressão advinda do sujeito, que ele menciona, não é a expressão do seu compositor enquanto "sujeito empírico individual", mas uma expressividade que anima (beseelt) a 
antes, o sujeito deve se tornar parte do organismo [...], pois o sujeito é o único componente da arte que não é mecânico, que é realmente vivo (ADORNO, 1998, p. 307)

Nesse sentido, quanto mais completamente uma obra é organizada, mais eloquente ela é, "uma vez que a ideia de uma organização completa se refere ao conteúdo da necessidade orgânica, e não da necessidade matemática". Essa nova forma, portanto, deveria nascer de um equilíbrio entre as necessidades impostas pelo material (coerência interna ao texto musical) e a organicidade advinda da intervenção do sujeito criador (liberdade). É pensando nesse equilíbrio que Adorno cunhou o termo "música informal" 9 ("musique informelle" no original em francês). Apesar das dificuldades de se definir tal conceito - ele escreve: "a música informal resiste à definição nos termos botânicos do positivismo" (ADORNO, 1998, p. 272) -, Adorno tenta delimitar alguns de seus parâmetros: "o que quero dizer [com o termo 'musique informelle'] é um tipo de música que descartou todas as formas que são externas ou abstratas, ou a qual se confronta com elas de maneira inflexível. Ao mesmo tempo, embora tal música possa ser completamente livre de qualquer coisa irredutivelmente externa ou sobreposta a si, não obstante, ela deve se constituir de maneira objetivamente convincente, na própria substância musical, e não em termos de leis externas" (ADORNO, 1998, p. 272). Para Adorno, uma "musique informelle" teria que facear o desafio posto por uma forma irrestrita onde estivesse assegurado o equilíbrio entre norma, coerência e liberdade.

Nostalgicamente, Adorno tenta ratificar sua proposta de "música informal" dando exemplos de obras do atonalismo

obra a partir da maneira que se estabelece a "articulação entre as notas".

9 O termo "informal" aparece aqui, não no sentido despretensioso que a palavra possa sugerir em português, mas como uma a-forma, uma organização regida pelo material em si, e não por uma formulação a priori. 
livre da década de 1910, tais como os Três Poemas Japoneses, de Stravinsky, ou o Erwartung, de Schoenberg. Para Adorno, o desenvolvimento de tal "estilo musical livre" foi interrompido, e os experimentos no campo no atonalismo livre foram sendo substituídos pela sistematização da técnica dodecafônica. Nas palavras de Adorno (1998, p. 276), "o enorme crescimento das forças produtivas da música [...] na simples habilidade de exercer controle sobre o certo e o errado [...] e tais avanços no controle sobre o material da música não podem mais ser revertidos". A "música informal" deveria construir novas categorias que pudessem, assim como o desenvolvimento temático e motívico na música do passado, auxiliar compositores a articular, e ouvintes a seguir, um discurso musical coerente e compreensível. Entretanto, não é fácil dizer exatamente como solucionar esse paradoxo. 0 próprio Adorno reconhece: "A fronteira entre uma objetificação desprovida de significado, a qual o compositor preenche de ouvidos fechados, 168 e uma composição que preenche a imaginação, transcendendoa, não é algo que possa ser elaborada de acordo com nenhuma regra abstrata" (ADORNO, 1998, p. 304).

Cabe aqui refletir de que modo os dois exemplos apresentados por Adorno são realmente elucidativos para a discussão de uma nova forma musical no século XX. Em primeiro lugar, as experiências do atonalismo livre mostraramse limitantes para o desenvolvimento temporal de discursos puramente musicais. Como vimos anteriormente, o próprio Schoenberg avalia tais obras como altamente "expressivas", contudo, "de uma brevidade notável". A limitação temporal da música do atonalismo livre é claramente expressa também no comentário que Webern fez sobre suas Bagatelas op. 9: "Eu sentia que, quando todas as doze alturas fossem usadas, a peça estaria terminada... Nos meus esboços, eu escrevi a escala cromática e riscava as notas individuais" (WEBERN apud BAILEY, 1998, p. 77). A proposta schoenberguiana de um novo método, dodecafônico, procurava atender, entre outras limitações composicionais, justamente à possibilidade de criar um discurso especificamente musical que se sustentasse ao logo do tempo e, ainda assim, permanecesse compreensível, tal como o sistema tonal tinha servido a duzentos e cinquenta anos 
de música. Foi justamente o dodecafonismo - que Adorno critica como sendo o início das práticas castradoras do sujeito criativo - que rearticulou a possibilidade de um macro-tempo para a Segunda Escola de Viena. Afinal, depois do período aforístico do atonalismo livre, empregando o método dodecafônico, Webern pôde escolher manter a concisão e brevidade, enquanto Schoenberg decidiu retomar suas obras em larga escala e Berg teve a liberdade de extravasar sua grandiloquência (MENEZES, 2006, p. 135-136).

A obra Erwartung, de Schoenberg, que Adorno elege como exemplo, só consegue chegar aos trinta minutos de duração porque a música está em diálogo com um texto. Como mostramos, Schoenberg tinha percebido a potencialidade das canções diante da limitação temporal das obras do atonalismo livre. Isso, justamente, porque nas canções, a estrutura do poema pode funcionar como um suporte formal para a música. É, portanto, significativo, que Adorno tenha escolhido dois exemplos provenientes da música vocal para ilustrar sua questão. De uma maneira ou de outra, é inevitável que a forma musical nesses casos deverá, senão respeitar, ao menos dialogar com a forma estabelecida pelo texto empregado na composição. Assim, é difícil definir até que ponto essas obras discutem uma liberdade formal especificamente musical e até que ponto elas aceitam a proposta formal do texto. 0 uso de música vocal para auxiliar a produção da Segunda Escola de Viena diante de seus dilemas formais é conhecido. Boulez percebe isso na trajetória de Webern: "observamos, aliás, quase sempre o mesmo fato no percurso de Webern; os principais períodos de sua vida criadora são marcados no início de sua evolução pelo emprego frequente, quase exclusivo, da música vocal" (BOULEZ, 1995, p. 325). E complementa: "Poderíamos dizer que, para organizar a música segundo estruturas novas, Webern experimenta a necessidade de se apoiar sobre um texto que lhe proporcione pontos de referência formais alheios a funções propriamente musicais." (BOULEZ, 1995, p. 327)

Mas se a proposta do atonalismo livre encontrou os seus limites já nas primeiras décadas do século XX, a proposta formal de Adorno - que tenta equilibrar a liberdade da escolha do sujeito e o respeito à coerência da articulação dos materiais 
da peça - permanece sem resposta prática. Sua proposta de música informal permanece isolada em uma "utopia", é um ideal sem uma solução palpável para os impasses vividos naquele momento. Ironicamente, Ligeti parece comentar justamente esse ideal de composição livre quando diz: "por que, então, seguir ainda manipulando serialmente? Não seria possível abandonar a forma, tanto em seu decurso global quanto em todos os seus detalhes, a mais desenfreada fantasia? 0 caráter regressivo de tais composições demonstra que essa liberdade seria falsa" (LIGETI, 2007, p. 94-95).

Ligeti vê, diante de tal dilema, a manutenção de alguma pré-estrutura, correlata à série, como uma possível solução e diz: "uma rede pré-formada de probabilidades e limitações parece assegurar a economia da utilização de material e da sensibilidade frente as repetições e periodicidades que se tornaram discutíveis ${ }^{10}$. Paradoxalmente, desse modo pode-se compor de forma mais livre que na liberdade total" (LIGETI, 2007, p. 95). Ligeti deixa claro, contudo, que ele não acredita em uma pré-estrutura como um paradigma imutável e soberano que subjuga o compositor a um papel burocrático de corresponder impensavelmente às suas leis. Seria, contudo, um recurso pelo qual um compositor poderia organizar a distribuição dos materiais escolhidos em um plano musical global, uma pré-estrutura que o ajudasse a imaginar um projeto formal de acordo com as buscas estéticas do momento. Em outras palavras, uma "rede pré-formada de probabilidades" que pudesse dar para o compositor elementos para evitar a teleologia e as hierarquias tonais, evitar o "caráter regressivo" que a livre fantasia poderia levar; que organizasse os materiais em um planejamento "descentralizado, não-hierárquico, com

${ }^{10}$ A preocupação com a economia dos materiais e sua articulação evitando redundâncias ecoa profundamente as colocações de Schoenberg a respeito da compreensibilidade do discurso musical: "Na esfera da arte musical, o autor respeita seu público. Ele tem medo de ofender pela repetição incessante daquilo que pode ser compreendido na primeira audição, mesmo quando se trata de um material novo, e mais ainda quando se trata de um material já desgastado" (SCHOENBERG, 2010, p. 401). 
uma distribuição equilibrada das indicações de controle que determinam a forma" (LIGETI, 2007, p. 93)

Em outras palavras, a série, que inicialmente ordenara apenas as alturas e que, mais tarde, tinha ordenado todos os elementos discretos da construção musical, deveria ser deslocada do detalhe para a grande forma. As organizações pré-composicionais deveriam estruturar o planejamento geral das obras. Quando necessário, as regras do planejamento inicial deveriam ser quebradas em favor das peculiaridades de cada trecho da obra. Esse deslocamento do lugar das prédeterminações na composição, segundo Ligeti, evitaria os nivelamentos do automatismo que impossibilitava a compreensibilidade das obras do início do serialismo integral:

0 entrelaçamento das pré-estabilizações seriais parece inclinar-se a um outro afrouxamento, a uma liquefação na qual a relação entre o plano de controle pré-formado e a forma daí resultante não permanece fixada e unilateral. Pelo contrário, o que é realizado reage continuamente sobre aquele plano de controle. Desse modo, o esboço perde a qualidade de uma pré-formação não obrigatória, continuando válidos, no entanto, seus contornos elásticos. Do automatismo e da entrega do material criado por nós mesmos, libertaria, pela primeira vez, um novo tipo de composição - e com ela uma forma - na qual seria possível ao compositor tomar, a todo momento, uma decisão que poderia conduzir o restante de todo o processo por um caminho totalmente diferente. (LIGETI, 2007, p. 95 - grifo nosso).

Experimentando tal concepção formal, Ligeti constrói tabelas de durações e suas possíveis quantidades para a peça Apparitions, para Orquestra (1958-59). Na sua conferência, Ligeti comenta sobre a peça:

Na primeira parte da minha obra orquestral "Apparitions", por exemplo, eu empreguei um repertório de durações (distância entre ataques) cujos elementos recebem uma atribuição de valores tais que o produto de cada valor de duração individual e do número de sua aparição na totalidade da estrutura resulta em uma constante. Assim, o equilíbrio das distâncias entre ataques é alcançado: quanto menor for um intervalo de duração particular, mais frequente ele aparecerá no contexto; assim, foram usadas 
várias durações curtas para cada duração longa, de modo que a soma das curtas se igualasse ao prolongamento de uma longa (LIGETI, 2007, p. 97)

Como vemos na explicação acima, Ligeti não adota, exatamente, uma série de durações. Em uma série de durações, a preocupação estaria na ordenação de figuras rítmicas distintas, onde cada duração apareceria uma única vez na sequência virtual de durações. Dessa maneira, como observa Ligeti, as durações longas se sobressairiam em relação às curtas, tomando mais tempo da linha temporal de uma obra. Neste exemplo simples, Ligeti mostra como o esquema organizacional de um parâmetro jamais pode ser impensadamente reproduzido por outro parâmetro, já que cada parâmetro sonoro tem suas implicações e suas características específicas. Ainda assim, as pré-formulações não precisam ser descartadas. Um projeto para as distâncias entre os ataques da peça levou-o a criar tabelas pré-composicionais

172 que garantiriam um equilíbrio entre durações longas e durações curtas ${ }^{11}$. As durações são, então, divididas entre as quatro seções nas quais a obra está segmentada, de modo que a soma das durações totais da peça corresponda, pelo menos em tese, às quantidades de cada figura rítmica estabelecida na tabela inicial. Já a relação entre as seções, segundo o projeto composicional da obra, respeitaria as proporções da seção áurea (LIGETI apud LEVY, 2006, p. 209). Como Ligeti sugere em sua palestra, aqui também a estrutura a priori é modificada para dar lugar às escolhas do compositor para atender as necessidades dos momentos específicos dentro da obra:

Um exame cuidadoso desses números revela que Ligeti mudou levemente a distribuição [das durações], deixando de fora nove exemplares do número 2 [semicolcheia], quatro do número 3 [semicolcheia pontuada]; duas do número 4

\footnotetext{
11 O trabalho de Benjamin Robert Levy (2006) apresenta esboços e análises de algumas das primeiras obras de Ligeti, quando o compositor chegou na Europa Ocidental, e discute a influência das práticas da música eletroacústica na escrita instrumental de Ligeti. Nesse trabalho, Levy traz as tabelas de durações que Ligeti usou na composição de Apparitions.
} 
[colcheia] e uma do número 10 [semínima ligada a semicolcheia] (LEVY, 2006, p. 209).

Da mesma maneira, o emprego do conceito de seção áurea, não é garantido em absoluta concordância com a proporção matemática, mas se aproxima dela. Assim, guiado por uma ideia global do que esperava de sua obra, e calculando as redes pré-estabelecidas, Ligeti garante o equilíbrio nãohierárquico do material rítmico (o que, para ele, seria a busca sonora de sua geração), sem se isentar do seu papel na tomada de decisões diante dos dilemas encontrados no caminho criativo.

Embora Ligeti e Adorno pareçam discordar em alguns detalhes a respeito dos melhores caminhos para a nova forma na segunda metade do século XX, a recepção de Adorno a uma das obras de Ligeti parece confirmar muitas concordâncias em seus juízos estéticos. "Ao rememorar aquela ocasião [quando Adorno ouviu pela primeira vez Atmosphères (1961) $\left.{ }^{12}\right]$, Ligeti afirmou que após ouvir a obra, Adorno teria exclamado que ela seria uma realização da musique informelle." (EDWARDS, 2015, p. 248).

No encontro no qual Adorno palestrou sobre seu conceito de "música informal" e Ligeti discorreu sobre como redes pré-estabelecidas poderiam ser deslocadas do detalhe para a organização formal (1965), Boulez critica seus companheiros palestrantes em colocações de humor fortemente ácido. ${ }^{13}$ Contudo suas colocações deixam pouco

\begin{abstract}
12 Ligeti escreve Atmosphères imediatamente depois de Apparitions, peça que comentamos logo acima. As duas são consideradas exemplos do mesmo período criativo de Ligeti, marcado pelo seu interesse pela saturação cromática e a manipulação de massas sonoras. A conclusão de Atmosphères, em 1961, está temporalmente localizada justamente entre a data de Apparitions (1958-59) e a palestra "Transformações da Forma Musical" (1965). Assim, o mesmo princípio formal que comentamos em Apparitions e está expresso nas palavras de Ligeti, também servem para entender Atmosphères.
\end{abstract}

${ }^{13}$ Cabe lembrar que esse texto não foi publicado ao lado dos outros textos ligados a esse encontro, em 1966. 
claro o seu posicionamento a respeito da dita nova forma musical. Apenas parece querer dizer que uma ideia de forma é intrínseca à vida (BOULEZ, 1990, p. 100) e sua discussão fica estagnada entre a vagueza filosófica e diretrizes de como seria melhor compor. Outros textos das décadas de 1950 e 1960 explicitam um pouco melhor sua opinião a respeito desse assunto.

Em Alea (1957) ${ }^{14}$, por exemplo, Boulez defende uma forma aberta. Algo que abrigasse uma porção controlada de indeterminação. Um meio termo entre as determinações do compositor, que jamais perderia as rédeas de sua obra, mas com incursões de surpresa e imprevisibilidade garantida pela escolha do intérprete em organizar as seções compostas. Contudo, ele alerta para a manutenção de um "fraseado geral". As obras deveriam "comportar sempre uma sigla inicial e um signo final, devem ainda apelar para certas espécies de 'plataformas' de bifurcação; isto para evitar uma perda total do sentido global da forma e também para impedir que se caia numa improvisação determinada apenas pelo livre-arbítrio [no momento da performance]" (BOULEZ, 1995, p. 50).

As escolhas do intérprete nas improvisações deveriam, portanto, ser controladas. "É bom lembrar, porém, o quanto essa liberdade precisa ser dirigida, protegida, já que a imaginação 'instantânea' é mais suscetível de falhar" (BOULEZ, 1995, p. 49). Assim, o compositor deveria construir pilares fixos que estruturassem o desenvolvimento temporal das obras, que assegurassem 'um 'percurso' problemático, função do tempo [...] que tem uma lógica de desenvolvimento, um sentido global dirigido [...] percurso que parte de um começo e chega a um fim" (BOULEZ, 1995, p. 52). As inserções de indeterminação seriam, então, como "cesuras" intercaladas à grande forma, como ornamentos que não afetam a compreensibilidade das notas estruturais de uma linha. E conclui afirmando: "Respeitamos o que a obra ocidental tem de 'acabado', o seu ciclo fechado, mas introduzimos a

14 Este texto está incluído na coletânea Apontamentos de Aprendiz (BOULEZ, 1995) 
'possibilidade' da obra oriental, seu desenvolvimento aberto" (BOULEZ, 1995, p. 52).

É o que ele propõe com sua Terceira Sonata para piano (1957-58). Boulez compõe seções como se fossem blocos que podem ser justapostos de diversas maneiras distintas. A ordenação dessas seções poderá ser escolhida pelo intérprete na hora de sua execução. Contudo, a peça deverá começar impreterivelmente pela seção $A$ - Antiphonie, terminar pela seção $E$ - Séquence, e exatamente no momento central da execução, as seções Constellation e Constellation miroir devem se seguir. Tal procedimento garante tanto a liberdade de escolha da construção formal durante a interpretação, quando a coerência formal, fundada, neste caso, no complexo simétrico do todo musical. Dessa maneira, o compositor se coloca em relação à obra e mantém o "fraseado geral" sob seu controle e arbítrio, planejado e refletido no momento da criação ao mesmo tempo que elementos de aleatoriedade enriquecem de surpresa o resultado de cada apresentação da obra. Logo, o domínio do sujeito, compositor, assim como da Obra de Arte acaba estaria, segundo Boulez, conservada ${ }^{15}$.

V.

Contrapondo-se às colocações dos outros participantes, o musicólogo alemão Carl Dahlhaus contextualiza o problema da forma na música em relação à crise do conceito de "obra" musical e às explorações de novos materiais sonoros em música. Além disso, o esteta critica as proposições formais levantadas até aqui, especialmente as de Adorno ("música informal") e de Boulez ("forma aberta").

Para Dahlhaus, o declínio do conceito de "obra" musical é muito anterior às discussões levantadas por Boulez.

\footnotetext{
${ }^{15}$ As colocações de Boulez em Alea respondem às propostas de Cage em relação à incursão de elementos aleatórios na música que, levadas às últimas consequências, destruiriam a própria noção de Obra de Arte (TERRA, 2000).
} 
Esse declínio está diretamente ligado, por um lado, ao declínio da ideia de "forma" e, por outro, à ênfase no material musical. A seu ver, "a significância da forma entra em declínio na mesma medida em que aumenta a significância do material" (DAHLHAUS, 1990, p. 228). Ou seja, quanto maior o papel do material na composição, maior o risco de que a forma se dissolva numa "mera justaposição de elementos desprovidos de relação entre si" (DAHLHAUS, 1990, p. 227). Além disso, com a expansão das fontes sonoras disponíveis - utilização de ruídos e misturas sonoras - a forma corre o risco de se fragmentar numa composição a partir dos sons [Klangkomposition], na qual "a diferenciação do material por meio dos ruídos significa uma perda de diferenciação funcional e formal" (DAHLHAUS, 1990, p. 228). Embora algumas categorias formais simples - tais como o contraste extremo, transição, repetição e variação - possam ser obtidas por meio dos ruídos, o autor considera que "as relações mais ricas e 176 complexas (contraste complementar, desenvolvimento e elaboração) só podem ser obtidas pelo uso de notas" (DAHLHAUS, 1990, p. 228). Dahlhaus parece concordar com as críticas adornianas ao uso da sonoridade "per se" (ADORNO, 1998, p. 277, nota de rodapé) e detecta na música de vanguarda algo análogo ao que ocorria na chamada "música trivial", a saber, a tendência à desintegração da estrutura em favor de uma mera concatenação de estímulos isolados (DAHLHAUS, 1990, p. 231).

Derivado das teorias formais do século XIX, o conceito de forma musical se torna problemático já desde o início do século XX, acentuando-se consideravelmente nas discussões estéticas pós-1950. Como notou Carl Dahlhaus, as teorias tradicionais da forma - baseadas nas distinções entre conteúdo e forma, bem como nas explicações da forma musical enquanto gênero (forma-canção, forma-rondó, forma sonata) - haviam sido abandonadas no século XX, "e seria anacrônico aderir a elas" (DAHLHAUS, 1990, p. 259). No entanto, tal declínio ocasionou uma série de problemas que exigiam uma solução, a saber: 1) a tendência a substituir o conceito de "forma" pela ideia de "estrutura"; 2) a questão das chamadas "formas abertas"; 3) a questão da "musique informelle". 
Quanto ao primeiro ponto, Dahlhaus (1990, p. 260) argumenta que o termo "forma" se refere ao delineamento do todo, enquanto o termo "estrutura" se refere mais aos detalhes da composição. Assim, a estrutura teria a ver com o "método" composicional, ao passo que a forma estaria mais relacionada com o "resultado" audível:

A estrutura tende a ser um conceito técnico, que sugere a gênese da obra, o processo de produção, enquanto a forma é uma categoria estética que se refere ao resultado, ao aspecto audível. Uma estrutura não precisa ser perceptível; o método não necessita ser aparente a partir do resultado. Por outro lado, a ideia de uma forma musical inaudível seria uma contradição em termos. A estrutura é o aspecto da obra voltado para o compositor, enquanto a forma está direcionada para o ouvinte (DAHLHAUS, 1990, p. 261).

Quanto ao segundo ponto, Dahlhaus argumenta que as "formas abertas", tal como concebidas por Boulez em sua Terceira Sonata para Piano, são fictícias, pois elas não existem para o ouvinte:

[0 ouvinte] não relaciona a versão que ele está ouvindo com outras versões possíveis que o instrumentista poderia ter escolhido. 0 que é uma forma variável no papel é algo fixo na performance. Uma vez que a forma é uma categoria que se refere ao resultado perceptível, e não ao método, a 'forma aberta' não pode ser considerada verdadeiramente 'aberta' (DAHLHAUS, 1990, p. 262).

Por fim, a crítica de Dahlhaus ao conceito de musique informelle é que, ao procurar se afastar da concepção de forma como padrões formais abstratos - isto é, a concepção de forma como 'fórmula' - acaba-se caindo num outro tipo de abstração "tão vazio quanto o primeiro" (DAHLHAUS, 1990, p. 263):

Pareceria que o objetivo da musique informelle seria chamar a atenção ao detalhe isolado, ao elemento musical individual. Pressupõe-se que aquilo que é dado acusticamente apareceria no puro presente, sem ligações com o passado ou o futuro. Contudo, é bastante duvidosa a possibilidade de cortar completamente a conexão entre momentos musicais individuais. A conexão não é eliminada, mas simplesmente se torna mais tênue e abstrata (DAHLHAUS, 1990, p. 263). 


\section{Considerações Finais}

Vimos ao longo deste artigo quatro pensadores que discutiram a música de seu tempo, seus problemas e proposições, no Curso de Versão de Darmstadt de 1965.

Theodor Adorno, György Ligeti e Pierre Boulez enxergam, os três, que o problema da música contemporânea estava fundado num mesmo ponto central: a abdicação do papel subjetivo do compositor durante o ato criativo. A exacerbação da busca por um formalismo irrepreensível, por uma objetividade extrema que exigia dos compositores da segunda metade do século XX completa coerência entre material empregado e construção formal, são fatores que teriam produzido uma crescente recusa desses compositores em mostrarem-se como sujeitos propositivos no ato da 178 composição (seja pelo deslocamento da responsabilidade das escolhas compositivas do sujeito criador para os esquemas matemáticos, seja pela destruição completa da ideia de "obra de arte" com a invasão do acaso até as últimas instâncias).

Como que respondendo à proposta de Eduard Hanslick em pensar a música a partir do "especificamente musical" e levando esse formalismo inicial do século XIX às últimas consequências, a geração de 1950 estaria se eximindo do próprio papel da criação artística. As propostas de musique informelle (Adorno), redes pré-estabelecidas para controle do texto musical como um todo, mas com manipulações do compositor nos momentos específicos das obras (Ligeti) ou a "forma aberta" (Boulez) são três propostas composicionais distintas que tentam resolver a questão do equilíbrio entre a coerência interna da obra, atendendo ao formalismo hanslickiano, mas sem perder do horizonte o papel subjetivo na construção da obra de arte musical. Claro está que tanto Adorno, como Ligeti e Boulez, estão criticando propostas composicionais que, para eles, não eram bem sucedidas e não de todo espectro musical.

Carl Dahlhaus é o único não-propositivo do encontro e, descontruindo o que os outros três falaram, ele aponta para 
uma questão nova para a música de seu tempo. Para o musicólogo, o problema da forma no século XX não passava pelo lugar do sujeito na criação artística, mas sim pelo deslocamento do interesse nas composições - da arquitetura musical até o século XIX, para o material discreto a partir do início do século XX, com a música de ruído, mas principalmente com as explorações da música concreta e eletrônica. Para ele, quanto mais complexos fossem os materiais musicais escolhidos, menos elaboradas poderiam ser as construções lógicas que organizariam esses materiais. Dessa maneira, sendo o sujeito propositivo ou não, a música do pós-1950 tinha que se deparar com a crise da forma musical e da "obra de arte".

\section{Referências bibliográficas}

ADORNO, T. W. Vers une musique informelle. In: Quasi una fantasia. New York: Verso, 1998.

. Berg: o mestre da transição mínima. São Paulo: Editora Unesp, 2010.

BAILEY, K. The twelve-note music of Anton Webern: old forms in a new language. Cambridge: Cambridge University Press, 1998.

BOULEZ, P. Apontamentos de aprendiz. São Paulo: Perspectiva, 1995.

Orientations. Collected writings. 2.a ed. Cambridge, MA: Harvard University Press, 1990.

DAHLHAUS, C. Schoenberg and the New Music. Cambridge: Cambridge University Press, 1990.

HANSLICK, E. Do Belo Musical. Campinas: Editora Unicamp, 1992.

EDWARDS, P. Convergences and discord in the correspondence between Ligeti and Adorno. In: Music and Letters, 96/2, abr., p. 228258, 2015.

LEVY, B. R. The electronic works of György Ligeti and their influence on his later style. Ph.D. University of Maryland, 2006.

LIGETI, G. Wandlungen der musikalischen Form. In: Gesammelte Schriften 1. Mainz: Schott, Paul Sacher Stiftung, 2007.

MENEZES, F. Micro-macrodirecionalidade em Webern: por uma análise direcional das Sechs Bagatellen Op. 9 de Anton Webern. In: 
Música maximalista: ensaios sobre a música radical e especulativa. São Paulo: Editora Unesp, 2006.

PALAND, R. “...eine sehr große Konvergenz?” Theodor W. Adorno und György Ligetis Darmstädter Formdiskurs. In: Blumröder, C. v. (ed.) Kompositorische Stationen des 20. Jahrhunderts. Debussy, Webern, Messiaen, Boulez, Cage, Ligeti, Stockhausen, Höller, Bayle. Münster: Lit Verlag, 2007.

SCHOENBERG, A. Style and Idea. Los Angeles: University of California Press, 2010.

STEWART, J. L. Ernest Krenek: the man and his music. Berkeley and Los Angeles: University California Press, 1991.

TERRA, Vera. Acaso e aleatório na música: um estudo da indeterminação nas poéticas de Cage e Boulez. São Paulo: Educ/FAPESP, 2000.

VIDEIRA, M. O Romantismo e o Belo Musical. São Paulo: Editora Unesp, 2006.

180 WEBERN, A. O caminho para a música nova. São Paulo: Novas Metas, 1984. 